\title{
Chemical Composition and Antimicrobial Activity of the Essential Oils of Two Aromatic Plants Cultivated in Morocco (Cinnamomum cassia and Origanum compactum)
}

\author{
Asmae Chahbi, ${ }^{1}$ Saâdiya Nassik, ${ }^{2}$ Hamid El Amri, ${ }^{3}$ Ahmed Douaik $\left(\mathbb{D},{ }^{4}\right.$ El Haj El Maadoudi, ${ }^{4}$ \\ Mohamed Boukharta, ${ }^{3}$ and El Mestafa El Hadrami $\mathbb{D D}^{1}$ \\ ${ }^{1}$ Laboratory of Applied Organic Chemistry (LCOA), Faculty of Sciences and Techniques, Sidi Mohamed Ben Abdellah University, \\ $\mathrm{Fez}$, Morocco \\ ${ }^{2}$ Avian Pathology Unit, Agronomic and Veterinary Institute Hassan II, Rabat, Morocco \\ ${ }^{3}$ Institute of Genetic Analysis of the Royal Gendarmerie, Rabat, Morocco \\ ${ }^{4}$ National Institute of Agricultural Research (INRA), Rabat, Morocco
}

Correspondence should be addressed to El Mestafa El Hadrami; elmestafa.elhadrami@usmba.ac.ma

Received 24 February 2020; Revised 15 May 2020; Accepted 27 May 2020; Published 13 June 2020

Academic Editor: Sevgi Kolaylı

Copyright $\odot 2020$ Asmae Chahbi et al. This is an open access article distributed under the Creative Commons Attribution License, which permits unrestricted use, distribution, and reproduction in any medium, provided the original work is properly cited.

\begin{abstract}
The present study aims to evaluate the antibacterial properties of natural products according to a pharmacodynamic approach in order to propose them as alternatives to synthetic products. Two essential oils (Cinnamomum cassia and Origanum compactum) were the subject of the chemical and biological study. First, we evaluated the sensitivity of the strains of avian Salmonella to the main antibiotics used and then to the chromatographic analysis of the composition of the two essential oils (EO); finally, we proceeded to the in vitro evaluation of the antibacterial activities of these EO (alone and in combination with antibiotics). The results obtained showed that carvacrol (35.2\%), followed by $\gamma$-terpinene (20.1\%), was the main constituent of the essential oil of $O$. compactum while cinnamaldehyde (69.1\%) represents the major component of the essential oil of $C$. cassia. The antibioresistance profile of the Salmonella tested showed resistance to ampicillin (35\%) and oxytetracycline (41.3\%). Active products extracted from the essential oils studied showed antibacterial activity against Salmonella strains. C. cassia products were shown to be more active for Salmonella enteritidis (average inhibition diameter: $16.3 \mathrm{~mm}$ ) and for Salmonella gallinarum (average inhibition diameter: $27.7 \mathrm{~mm}$ ). The best synergistic activity with antibiotics has been obtained with the essential oil of C. cassia and its active product cinnamaldehyde. The minimum inhibitory concentration (MIC) of cinnamaldehyde is the lowest (0.05\%). The results prove the presence of an antibacterial activity and a synergistic effect of two essential oils studied with the main antibiotics.
\end{abstract}

\section{Background}

Salmonellosis is the most common foodborne bacterial disease worldwide. The bacteria responsible belongs to the family of Enterobacteriaceae and the genus Salmonella and is a Gram negative, optional anaerobic, and most often mobile [1-3].

Currently, there are approximately 2610 Salmonella serotypes determined by their $O$ and $H$ antigenic structures and classified according to the Kauffmann-White classification updated annually [4].

Salmonella is a predominant cause of food infections. One study estimated that they were responsible for 93.8 million human cases of gastroenteritis and 155,000 deaths worldwide every year [5].

Furthermore, according to the European Food Safety Authority (EFSA) and the European Center for Disease 
Prevention and Control (ECDC), salmonellosis was the second most frequently reported gastrointestinal infection for people in the European Union in 2018 (91,857 cases), after campylobacteriosis (246,571 cases). https://www.efsa. europa.eu/fr/news/salmonella-most-common-cause-

foodborne-outbreaks-european-union.

The misuse of antimicrobial agents has led to the emergence of resistant bacteria. This resistance to antibiotics represents a serious problem to human health [6]. The majority of antibiotic resistance is due to the genes that could be expressed in any bacteria. This notion is illustrated by the term "resistome" which defines the set of antibiotic resistance genes that can be found in environmental bacteria as well as in pathogenic bacteria [7].

Salmonella resistance to commonly used antimicrobials (such as tetracyclines, sulfonamides, ampicillin, and fluoroquinolones) has been detected in humans and also in poultry [8].

The kentucky and infantis Salmonella serotypes are of concern because they show a high level of resistance to ciprofloxacin as well as multiresistance to several other drugs [9]. Multiresistance is particularly observed for the strains of the Salmonella typhimurium serotype [10].

In Morocco, studies conducted in the Tetouan region have shown that $39.6 \%$ of Salmonella strains tested are resistant to at least one antibiotic and $22.9 \%$ are multiresistant to at least three antibiotics [11]. In the RabatCasablanca region, a study showed relatively low resistance rates for colistin (10.5\%) and gentamicin $(8.8 \%)$. The trimethoprim-sulfamethoxazole combination has been shown to be active on most strains (resistance rate $=3.5 \%$ ) [12]. In the Casablanca region, antibiotic resistance of Salmonella kentucky showed slightly high resistance rates: tetracycline (99.5\%), nalidixic acid and flumequine (26.9\%), ciprofloxacin (24.6\%), amoxicillin (19.4\%), gentamicin (16.4\%), sulfonamides-trimethoprim (13.4\%), cefquinome (8.2\%), and colistin (1.5\%) [13].

Alongside prevention measures, scientific research has oriented towards the development of new molecules not or hardly subject to the phenomenon of resistance and towards the discovery of products capable, by synergistic effect, of restoring sensitivity to already existing antibiotics.

In addition, in order to preserve the health of the consumer and to delay the wear of antibacterials without compromising the production performance of the chicken, chemicals based on extracts of aromatic plants can constitute a complete or partial alternative to the usual antibiotics $[14,15]$.

However, as with all products used for human or animal health, rational use of natural products must be done on the basis of pharmacological, toxicological, and clinical studies.

This work aims, on the one hand, to contribute to the study of the resistance to antibiotics of Salmonella of the animal origin, to evaluate the antibacterial properties of essential oils of cinnamon (C. cassia) and oregano (O. compactum), as well as their main active components (cinnamaldehyde and carvacrol), and, on the other hand, to study their possible interactions with usual antibiotics.

\section{Materials and Methods}

\subsection{Biological Materials}

2.1.1. Aromatic Plants. The aromatic plants C. cassia and $O$. compactum (Figures 1(a) and 1(b)) were collected in 2018, at the Rabat region. The samples obtained were kept at $4^{\circ} \mathrm{C}$ until the time of analysis. The extraction of essential oils from the samples was carried out at the laboratory of the Department of Food Sciences of the Agronomic and Veterinary Institute (IAV Hassan II). The reference cinnamaldehyde (Sigma-Aldrich, 99\%) and carvacrol (SigmaAldrich, $>98 \%$ ) were provided by the same department.

2.1.2. Salmonella. The bacterial strains tested were isolated from autopsies of laying hens from different regions of Morocco. The samples were taken and identified at the Avian Pathology Unit of IAV Hassan II by Nassik et al. [18].

Isolated bacteria were conserved at $+4^{\circ} \mathrm{C}$ and kept alive by continuous subcultures on the agar trypticase soya (TSA) medium. Twenty one (21) strains were tested: ten (10) strains of Salmonella enteritidis, ten (10) strains of Salmonella gallinarum (sensitive to florfenicol and resistant to oxytetracycline and amoxicillin), and one reference strain of Salmonella (CTP 8059) provided by the Pasteur Institute of Casablanca/Morocco.

2.2. Extraction of Essential Oils. The essential oils were extracted from the aerial parts of $O$. compactum and the bark of C. cassia, by hydrodistillation for three hours using the Clevenger-type apparatus. The distilled essential oils had been dehydrated with anhydrous sodium sulphate and stored at $4^{\circ} \mathrm{C}$ in dark, airtight bottles [19].

The oil yield was express as a percentage and calculated according to the following formula:

$$
\operatorname{Rdt}_{\mathrm{EO}}:\left(\frac{M_{\mathrm{EO}}}{M_{V}}\right) * 100,
$$

where $\mathrm{Rdt}_{\mathrm{EO}}$ is the yield in the essential oil (\%), $M_{\mathrm{EO}}$ is the mass of the essential oil (g), and $M_{V}$ is the mass of the dry plant material (g).

2.3. Chemical Analysis of Essential Oils. A gas chromatograph (CLARUS 580) mounted on a mass spectrometer (Clarus SQ 8S) and operating in the positive electronic impact mode (70 ev) and a VB-5 column (5\% phenyl and $95 \%$ methyl polysiloxane), $30 \mathrm{~m}$ long, $0.25 \mathrm{~mm}$ internal diameter, and $0.25 \mathrm{~mm}$ thick, were used.

The temperatures of the injector and the detector were 250 and $300^{\circ} \mathrm{C}$. The gas used is helium at a flow rate of $1 \mathrm{ml} /$ min. The program temperature is from 50 to $280^{\circ} \mathrm{C}$ with a gradient of $8.1^{\circ} \mathrm{C} / \mathrm{min}$. Component identification was done using the combination of the NIST-MS Research Program and the PubChem database (https://pubchem.ncbi.nlm.nih. gov/). 


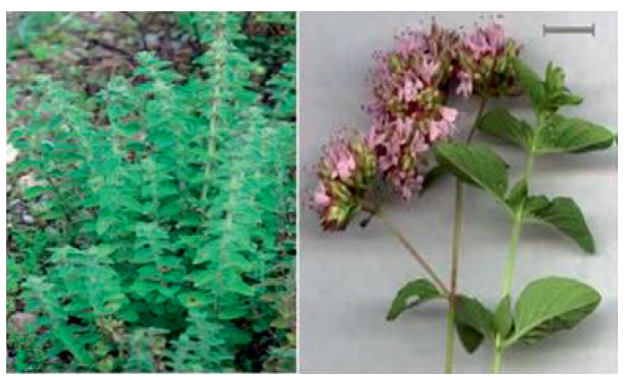

(a)

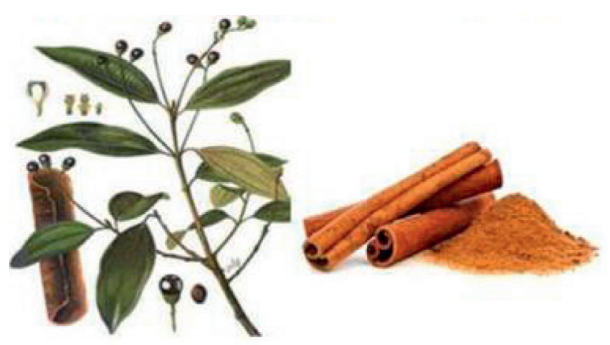

(b)

Figure 1: (a) O. compactum and (b) C. cassia $[16,17]$.

2.4. Antibiogram. The antibiogram was carried out by the method of diffusion on the Mueller-Hinton agar medium. Some colonies are taken and diluted in sterile physiological water (dilution of $1 / 10$ on a scale of 0.5 MacFarland). The antibiotic discs are deposited separately, and then the dishes are incubated at $37^{\circ} \mathrm{C}$ for 24 hours.

Eight antibiotics are used: florfenicol, thiamphenicol, enrofloxacin, amoxicillin, oxytetracycline, sulfamethoxazole-trimethoprim, erythromycin, and colistin.

2.5. Evaluation of Antibacterial Activity. The antibacterial activity of the essential oil was determined by the diffusion method on agar (Muller-Hinton) [20]. Two controls were performed: a negative control with $10 \mu \mathrm{l}$ of sterile distilled water in the presence of $10 \%$ DMSO and a disk representing one of the antibiotics as a positive control. The dishes are incubated at $37^{\circ} \mathrm{C}$ for 18 to 24 hours. Next, the diameter of inhibition is measured in millimeters.

\subsection{Determination of Minimum Inhibitory Concentration.} The minimum inhibitory concentration (MIC) was determined by the microdilution technique on a 96-well roundbottomed microplate [21], using resazurin as an indicator of viability [22]. A series of half dilutions of the essential oil (1/ $2,1 / 4,1 / 8$, and up to $1 / 512$ ) were prepared at a concentration range from $1 \%$ to $0.00195 \%$, with the concentration of the stock solution of each oil being $1 \mu \mathrm{l} / 100 \mu \mathrm{l}$. The dilution method consists of preparing a series of wells containing tryptic soy broth (TSB). The wells are filled with $69 \mu \mathrm{l}$ of TSB. Then, $1 \mu \mathrm{l}$ of essential oil is added to the first one and then a dilution is made. Then, each well is inoculated with $25 \mu \mathrm{l}$ of the bacterial suspension. The wells used as a negative control do not contain essential oil, and those used as a positive control contain essential oil without bacterial suspension. The microplates were incubated at $37^{\circ} \mathrm{C}$ for $18-24$ hours. For MIC revelation, $5 \mu \mathrm{l}$ of resazurin $0.01 \%(\mathrm{w} / \mathrm{v})$ was added to each well. The MIC was defined as the lowest concentration of oil that did not produce a color change in the resazurin and corresponds to the absence of bacterial growth.

\subsection{Determination of Minimum Bactericidal Concentration} $(M B C)$. The MBC is calculated using $10 \mu \mathrm{l}$ of wells, which have not shown bacterial growth on a solid medium after seeding and incubation at $37^{\circ} \mathrm{C}$ for $24-48 \mathrm{~h}$. The $\mathrm{MBC}$ is considered the minimum concentration of essential oil for which no bacterial development is observed.

2.8. Interactions between Essential Oils, Their Majority Compounds, and Antibiotics. The association of essential oils and their majority compounds with antibiotics was evaluated by the method of diffusion by discs in the solid medium recommended by Halawani and Toroglu $[23,24]$. This involves comparing the inhibitory activity on a strain of Salmonella using three discs: the first is an antibiotic disc (ATB), the second is a sterile neutral disc soaked in $5 \mu \mathrm{l}$ of essential oil (EO) or the majority compound (PA) to be tested, and the third is an antibiotic disc soaked with $5 \mu \mathrm{l}$ of the same essential oil or of its majority compound to be tested.

After incubation, the reading of three inhibition diameters in $\mathrm{mm}$ is carried out using a ruler. The data were analyzed according to the following three possibilities:

A: indifference: the zones of inhibition of EO/PA alone, $\mathrm{ATB}$ alone, and the association $\mathrm{EO}+\mathrm{ATB}$ remain unchanged

B: antagonism: the inhibition zone of the $\mathrm{EO}+\mathrm{ATB}$ association is less important than that of the $\mathrm{EO} / \mathrm{PA}$ alone and the ATB alone

C: synergy: the inhibition zone of the $\mathrm{EO}+\mathrm{ATB}$ association is more important than that of the $\mathrm{EO} / \mathrm{PA}$ alone and the ATB alone

2.9. Data Analysis. The method of analysis of variance (ANOVA) was used to test the effects of factors on the variables measured (diameter and percentage \%). If we reject the null hypothesis of equality of means, we use Duncan's multiple comparison tests of means to form homogeneous groups of essential oils and active ingredients that do not differ between them. For the variables in percentage (MIC and $\mathrm{MBC}$ ), we transformed them with the angular transformation before performing the ANOVA. These analyzes were carried out using the SAS software (SAS, 2006).

\section{Results}

3.1. Essential Oil Yield. The essential oil of the bark of the cinnamon of China (C. cassia) is a yellowish liquid with a strong and characteristic odor with a yield of $1.18 \%(\mathrm{w} / \mathrm{w})$. 
The essential oil of $O$. compactum was calculated based on the dry plant matter of the aerial part of the plant and had a yield of $1.6 \%$.

3.2. Chemical Composition. For the essential oil of $O$. compactum, ten (10) constituents have been identified, the majority of which are carvacrol $(35.17 \%)$, followed by $\gamma$-terpinene $(20.09 \%)$, thymol (17.5\%), and o-cymene (13.7\%), representing $86.48 \%$ of the oil (Table 1 and Figure 2(a)).

For the essential oil of $C$. cassia, four components have been identified. Cinnamaldehyde is the main compound (69.15\%), followed by methoxycinnamic acid $(21.18 \%)$, benzyl alcohol (6.14\%), and benzyl benzoate (3.53\%) (Table 2 and Figure 2(b)).

The number of components identified in the essential oil of $C$. cassia in our study is much smaller than that reported in some previous studies [25].

3.3. Antibiotypy. Figure 3 represents the percentages of resistance of the strains of Salmonella tested to antibiotics. Erythromycin has shown the maximum resistance (100\%), which shows that Salmonella are naturally resistant to this antibiotic [26].

The resistance of the strains studied to oxytetracycline was $41.28 \%$ and $35 \%$ to amoxicillin, while enrofloxacin and trimethoprim-sulfamethoxazole had a resistance percentage of ,approximately, 23 and 13\%, respectively. Thiamphenicol showed 9\% resistance. However, colistin (25 and $50 \mu \mathrm{g}$ ) showed a resistance of $5 \%$ as well as florfenicol (5\%).

\subsection{Evaluation of Antibacterial Activity by the Disc Diffusion} Method. Aromatograms were performed first on a reference strain (Salmonella CTP 8059) and then on strains of Salmonella enteritidis and Salmonella gallinarum of the avian origin.

The results are expressed by the diameters of the inhibition zones. According to Meena and Sethi and Ela et al. $[27,28]$, susceptibility to an essential oil was classified according to inhibition zone diameters as follows:

(i) EO strongly inhibitory: diameter of the inhibition zone $>28 \mathrm{~mm}$

(ii) EO moderately inhibitory: diameter of the zone between 16 and $28 \mathrm{~mm}$

(iii) EO slightly inhibitory: diameter of the zone varies between 10 and $16 \mathrm{~mm}$

(iv) EO noninhibiting: inhibition diameter is less than $10 \mathrm{~mm}$

3.4.1. Reference Strain. The results of the antibacterial activity of essential oils and majority compounds were studied on the reference strain (Table 3 ). The null hypothesis $\left(H_{0}\right)$ assumes that the mean inhibition diameters of the essential oils and majority compounds are equal. Since the probability
TABLE 1: Chemical composition of the O. compactum essential oil.

\begin{tabular}{lcc}
\hline Retention time $(\mathrm{min})$ & Constituents & Percentage \\
\hline 6.792 & 3-Methyl-apopinene & 0.848 \\
7.922 & Myrcene & 1.953 \\
8.476 & 4-Carene & 2.267 \\
8.647 & o-Cymene & 13.669 \\
9.360 & $\gamma$-Terpinene & 20.089 \\
10.102 & Linalool & 4.146 \\
13.675 & Thymol & 17.553 \\
13.896 & Carvacrol & 35.173 \\
15.976 & Caryophyllene & 3.111 \\
18.519 & Caryophyllene oxide & 1.193 \\
Total & & 100 \\
\hline
\end{tabular}

Table 2: Chemical composition of the C. cassia essential oil.

\begin{tabular}{lcc}
\hline Retention time $(\mathrm{min})$ & Constituents & Percentage \\
\hline 8.814 & Benzyl alcohol & 6.137 \\
13.508 & Cinnamaldehyde & $\mathbf{6 9 . 1 4 6}$ \\
15.550 & Methoxycinnamic acid & $\mathbf{2 1 . 1 8 8}$ \\
20.974 & Benzyl benzoate & 3.529 \\
Total & & 100 \\
\hline
\end{tabular}

value ( $p$ value) is less than $0.05, H_{0}$ is rejected and the mean inhibition diameters are different.

Based on the results of Duncan's test, three different groups of essential oils were identified:

(i) The $1^{\text {st }}$ group composed only of cinnamaldehyde, which gave the best average diameter of inhibition $(30.3 \mathrm{~mm})$

(ii) The $2^{\text {nd }}$ group is composed of the essential oil of $C$. cassia and carvacrol with average inhibition diameters of 25 and $24.7 \mathrm{~mm}$

(iii) The $3^{\text {rd }}$ group is composed only of the O. compactum which gave the smallest diameter $(21 \mathrm{~mm})$

The essential oil of C. cassia (mean inhibition diameter $25 \pm 2 \mathrm{~mm}$ ) and cinnamaldehyde (mean inhibition diameter $30.0 \pm 1.5 \mathrm{~mm})(p<0.005)$ showed a higher antibacterial activity than the essential oil of $O$. compactum (mean inhibition diameter $21 \pm 2 \mathrm{~mm})(p<0.005)$ and carvacrol (mean inhibition diameter $24.6 \pm 1.5 \mathrm{~mm}$ ). This indicates that the bacterial strain is more sensitive to C. cassia essential oil and cinnamaldehyde than to O. compactum essential oil and carvacrol.

3.4.2. Wild Strains of Avian Origin. The null hypothesis $H_{0}$ means that the average diameters of inhibition of essential oils and majority compounds are equal and there is no interaction between strains and essential oils. If the probability value ( $p$ value) is less than $0.05, H_{0}$ is rejected and the mean inhibition diameters are different.

Initial qualitative tests of essential oils and their majority compounds on the strains studied, using the agar diffusion method, resulted in zones of inhibition (Table 4).

The ANOVA indicates that there are highly significant differences between the two strains $(F$ value $=265.73$ and $p$ 


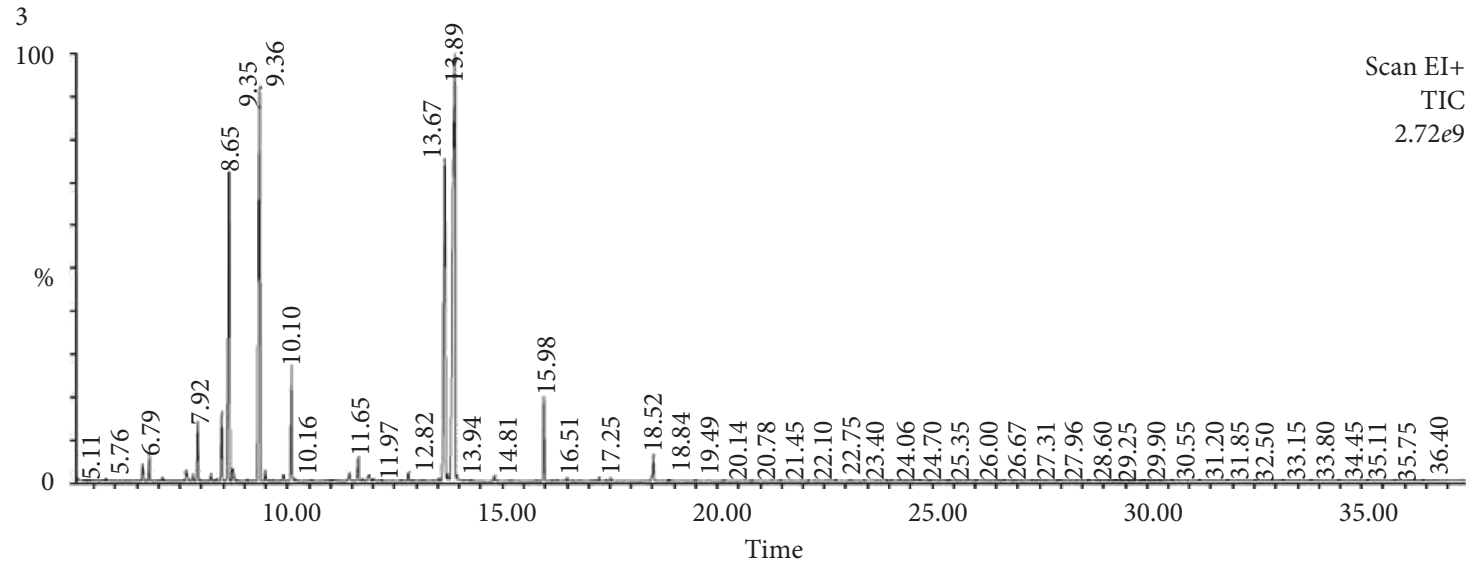

(a)

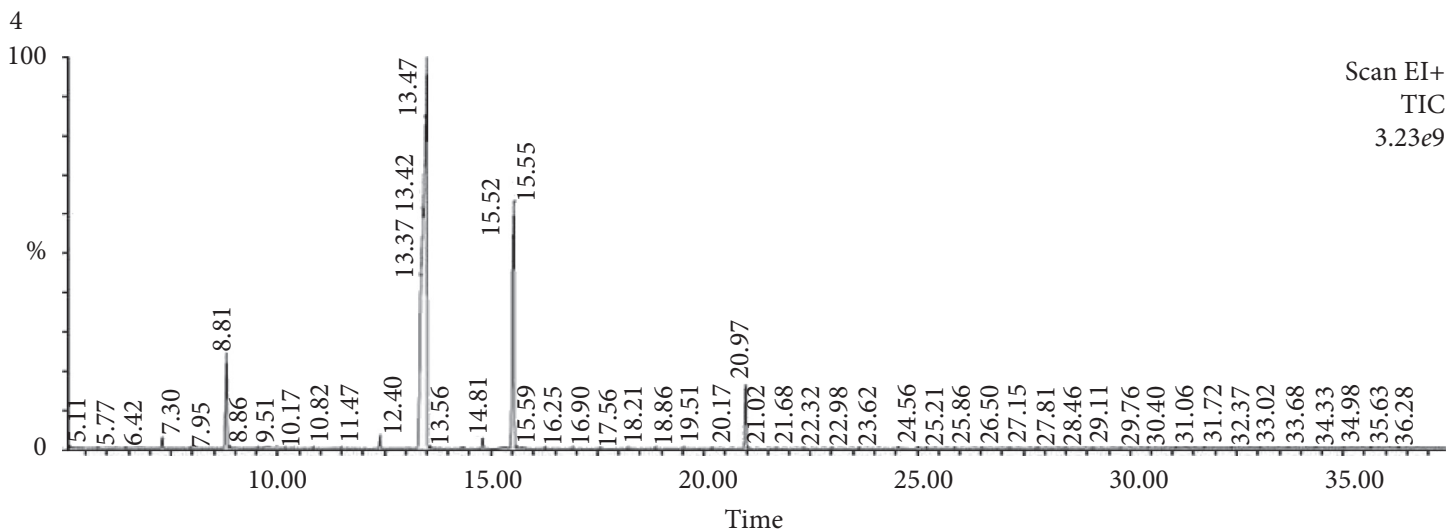

(b)

Figure 2: Qualitative report of the essential oil of (a) oregano and (b) cinnamon.

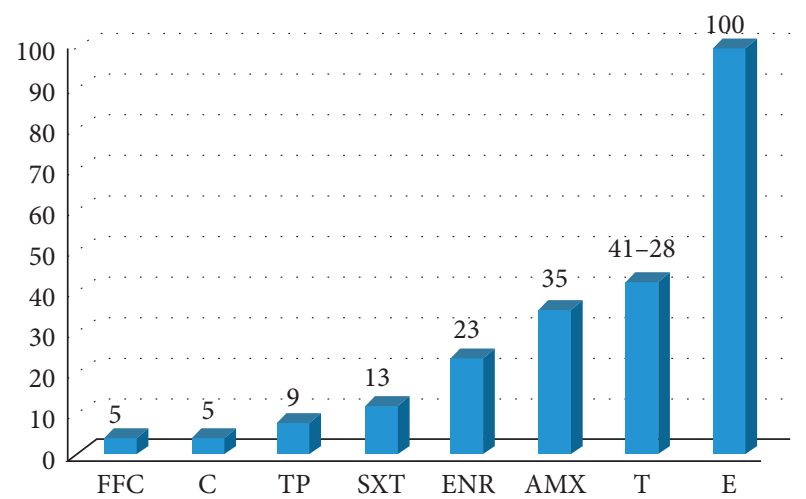

Resistance of Salmonella to antibiotics

Figure 3: Percentage of Salmonella resistant to antibiotics. E, erythromycin; T, oxytetracycline; AMX, amoxicillin; ENR, enrofloxacin; SXT, trimethoprim-sulfamethoxazole; TP, trimethoprime; C, colistin; FFC, florfenicol.

value $<0.0001$ ), between the four majority compounds ( $F$ value $=23.02$ and $p$ value $<0.0001$ ), and a significant interaction between these two factors $(F$ value $=32.11$ and $p$ value $<0.0001)$.
The essential oil of C. cassia presents, on average, the highest inhibitory activity on both strains (average inhibition diameter $22 \mathrm{~mm}$ ) compared to the essential oil of $O$. compactum and carvacrol (average inhibition diameter 17.7 and $17.3 \mathrm{~mm}$ ). However, this activity varies from strain to strain. Indeed, Salmonella gallinarum is more sensitive to the essential oil of C. cassia (average diameter of inhibition $27.7 \mathrm{~mm}$ ) than the strain of Salmonella enteritidis (average diameter of inhibition $16.3 \mathrm{~mm}$ ).

The activity of the essential oil of $C$. cassia (average inhibition diameter $22 \mathrm{~mm}$ ) is, on average, more powerful than that of cinnamaldehyde (average inhibition diameter $18.9 \mathrm{~mm}$ ).

However, carvacrol seems to be more active (inhibition diameter $21.4 \mathrm{~mm}$ ) than the essential oil of O. compactum (inhibition diameter $17.7 \mathrm{~mm}$ ) for Salmonella gallinarum which can be justified by its low content in the composition of the essential oil (35.2\%) or the presence of carvacrol antagonistic compounds in the essential oil of $O$. compactum [29].

3.5. Determination of Minimum Inhibitory and Bactericidal Concentrations. Table 5 shows the results of the minimum inhibitory concentrations (MIC) and minimum bactericidal 
TABle 3: Diameters $(\mathrm{mm})$ of the zones of inhibition obtained with the reference strain Salmonella CTP 8059.

\begin{tabular}{lcccccc}
\hline Agents & EO of O. compactum & Carvacrol & EO of C. cassia & Cinnamaldehyde & $F$ & $p$ value \\
\hline Mean & $21.0 \mathrm{c}$ & $24.7 \mathrm{~b}$ & $25.0 \mathrm{~b}$ & $30.3 \mathrm{a}$ & 13.99 & 0.0015 \\
SD & 2.0 & 1.5 & 2.0 & 1.5 & 13.99 \\
\hline
\end{tabular}

TABle 4: Diameters (mm) of the zones of inhibition obtained with wild strains of Salmonella enteritidis and Salmonella gallinarum of the avian origin.

\begin{tabular}{|c|c|c|c|c|c|c|}
\hline \multirow[b]{2}{*}{ Strains } & \multicolumn{6}{|c|}{$\mathrm{EO}$} \\
\hline & C. cassia & Cinnamaldehyde & O. compactum & Carvacrol & Mean & $\begin{array}{c}F \text { value } \\
(p \text { value })\end{array}$ \\
\hline S. enteritidis & $16.3 \mathrm{~b}$ a & $14.4 \mathrm{~b} \mathrm{c}$ & $17.7 \mathrm{a}$ & $13.3 \mathrm{c}$ & 15.4 & \\
\hline S. gallinarum & $27.7 \mathrm{a}$ & $23.5 \mathrm{~b}$ & $17.7 \mathrm{~d}$ & $21.4 \mathrm{c}$ & 22.5 & $265.73(<0001)$ \\
\hline Mean & $22.0 \mathrm{a}$ & $18.9 \mathrm{~b}$ & $17.7 c b$ & $17.3 \mathrm{c}$ & 19.0 & \\
\hline$F$ value ( $p$ value $)$ & \multicolumn{5}{|c|}{$23.02(<0.0001)$} & \\
\hline
\end{tabular}

concentrations (MBC) of the two essential oils and their majority compounds on the two bacterial strains.

According to the ANOVA results, there are significant differences only between the essential oils for the two parameters measured (MIC and MBC) $(F$ value $=10.45$ and $p$ value $=0.0005 ; \quad F$ value $=22.55$ and $p$ value $<0.0001)$, whereas there is no significant difference between the two strains and no significant interaction between the strains and the essential oils.

In a liquid medium, the essential oil of C. cassia was, on average, the most effective, and its effect was also very stable (MIC $0.018 \%$ and MBC $0.026 \%$ ). The essential oil of O. compactum was less effective than that of C. cassia (MIC $0.114 \%$ and MBC 0.167\%). Similarly, cinnamaldehyde presented MICs of 0.04 and $0.05 \%$, thus showing a strong antibacterial activity on the strains studied, thus translating a better antibacterial activity of the essential oil of $C$. cassia, which can be explained by the combined effect of cinnamaldehyde $(69.15 \%)$ and other minority compounds [30].

The results obtained for the MICs are for the majority in concordance with the diameters of the inhibition zones observed in the agar diffusion test. On the other hand, all the products tested showed bactericidal activity, and the values of MBCs were similar or almost similar to those of MIC (with mean MIC of $0.076 \%$ and mean MBC of $0.10 \%$ ). C. cassia exhibited the highest inhibitory and bactericidal activity against both strains.

3.6. Interaction of Essential Oils-Antibiotics. We have associated each essential oil and each active principle with different antibiotics to which the Salmonella strain exhibits resistance, namely, oxytetracycline and amoxicillin, to qualitatively determine the possible interactions between essential oils as well as their active principles and antibiotics (Table 6).

According to the ANOVA results, there are significant differences between bacterial strains $(F$ value $=976.82$ and $p$ value $<0.0001)$, products $(F$ value $=223.45$ and $p$ value $<0.0001)$, and products used $(F$ value $=76.05$ and $p$ value $<0.0001)$. Similarly, all interactions are significant except that between the strains and the products used ( $F$ value $=0.60$ and $p$ value $=0.5787)$.

The analysis of the data obtained shows that the association of the essential oil of $O$. compactum with oxytetracycline gave synergistic interactions $(18 \mathrm{~mm})$ compared to that of the essential oil alone $(14.5 \mathrm{~mm})$ and the antibiotic alone on both strains of Salmonella, while a slight antagonistic effect was obtained with amoxicillin $(9 \mathrm{~mm})$ compared to the essential oil alone (14.5 and $22 \mathrm{~mm}$ ).

Table 6 shows an antagonistic interaction when combining carvacrol with amoxicillin $(15.75 \mathrm{~mm})$; however, synergy is achieved with oxytetracycline $(20 \mathrm{~mm})$.

The results show a synergistic interaction of the essential oil of C. cassia (23 and $22.75 \mathrm{~mm}$ ) and cinnamaldehyde (21.5 and $20 \mathrm{~mm}$ ) with all the antibiotics tested.

From the results cited above, we found that the essential oil of $C$. cassia and cinnamaldehyde were the most active in combination with antibiotics, and this result shows a synergistic effect.

\section{Discussion}

The study of the chemical composition of essential oils has shown that the majority constituents of the essential oil of $O$. compactum are carvacrol (35.17\%), followed by $\gamma$-terpinene (20.09\%), thymol (17.55\%), and o-cymene (13.67\%), accounting for $86.48 \%$ of the oil. These results are in agreement with those obtained in the study by Ben-Hammou et al. which showed that the most abundant compound in the chemical composition of this essential oil is carvacrol (36.31\%), followed by thymol (16.88\%) and $p$-cymene (9.21\%) [31].

Furthermore, the analysis of essential oils of O. compactum from different regions of Morocco revealed the presence of three main components at variable rates: thymol ( 0 to $43.4 \%$ ), carvacrol ( 3.8 to $71 \%$ ), and $p$-cymene (0 to $25.4 \%)[32,33]$.

For the essential oil of C. cassia, the study showed that cinnamaldehyde is the main compound (69.15\%), followed by methoxycinnamic acid (21.19\%), benzyl alcohol (6.14\%), and benzyl benzoate $(3.53 \%)$. These results are consistent with those reported in previous studies [34, 35]. Tao et al. 
TABLE 5: Minimum inhibitory concentrations (MIC) and minimum bactericidal concentration (MBC) (\%) (v/v) means of the essential oils tested and their majority compounds according to the Salmonella strain.

\begin{tabular}{|c|c|c|c|c|c|c|c|}
\hline Variable & Agent/strain & C. cassia & Cinnamaldehyde & O. compactum & Carvacrol & Mean & $\begin{array}{c}F \text { value } \\
(p \text { value })\end{array}$ \\
\hline \multirow{4}{*}{ MIC } & S. enteritidis & $0.02 \mathrm{~b}$ & $0.05 \mathrm{~b}$ a & $0.10 \mathrm{~b}$ a & $0.14 \mathrm{a}$ & $0.08 \mathrm{a}$ & \multirow{4}{*}{$0.16(0.6920)$} \\
\hline & S. gallinarum & $0.02 \mathrm{~b}$ & $0.04 \mathrm{~b}$ & $0.13 \mathrm{a}$ & $0.10 \mathrm{a}$ & $0.07 \mathrm{a}$ & \\
\hline & Mean & $0.02 \mathrm{~b}$ & $0.05 \mathrm{~b}$ & $0.11 \mathrm{a}$ & $0.13 \mathrm{a}$ & 0.076 & \\
\hline & $\begin{array}{l}F \text { value } \\
(p \text { value })\end{array}$ & \multicolumn{5}{|c|}{$10.45(0.0005)$} & \\
\hline \multirow{4}{*}{$\mathrm{MBC}$} & S. enteritidis & $0.03 \mathrm{~b}$ & $0.03 \mathrm{~b}$ & $0.20 \mathrm{a}$ & $0.16 \mathrm{a}$ & $0.11 \mathrm{a}$ & \multirow{4}{*}{$2.97(0.1040)$} \\
\hline & S. gallinarum & $0.05 \mathrm{c}$ & $0.05 \mathrm{~b}$ & $0.13 \mathrm{a}$ & $0.13 \mathrm{a}$ & $0.08 \mathrm{a}$ & \\
\hline & Mean & $0.03 \mathrm{~b}$ & $0.04 \mathrm{~b}$ & $0.17 \mathrm{a}$ & $0.15 \mathrm{a}$ & 0.10 & \\
\hline & $\begin{array}{l}F \text { value } \\
(p \text { value })\end{array}$ & & & $5(<0.0001)$ & & & \\
\hline
\end{tabular}

TABLE 6: Evaluation, by the disc method, of the effects of essential oils, active products, and antibiotics on the inhibition diameter (mm).

\begin{tabular}{|c|c|c|c|c|c|c|c|c|}
\hline $\begin{array}{l}\text { Bacterial } \\
\text { strains }\end{array}$ & Products used & $\begin{array}{l}\text { EO of } O . \\
\text { compactum }\end{array}$ & $\begin{array}{c}\text { EO of } C . \\
\text { cassia }\end{array}$ & Carvacrol & Cinnamaldehyde & Oxytetracycline & Amoxicillin & Mean \\
\hline \multirow{4}{*}{ S. gallinarum } & Oxytetracycline & 22 & 29 & 25 & 26 & - & - & \multirow{4}{*}{$\begin{array}{c}22.1 \\
\mathrm{~A}\end{array}$} \\
\hline & Amoxicillin & 16 & 29 & 19.5 & 25 & - & - & \\
\hline & $\begin{array}{l}\text { Without antibiotic } \\
\text { (nothing) }\end{array}$ & 18 & 28 & 21 & 23 & - & - & \\
\hline & Antibiotic alone & - & - & - & - & 19 & 9 & \\
\hline \multirow{4}{*}{ S. enteritidis } & Oxytetracycline & 14 & 17 & 16 & 17 & - & - & \multirow{4}{*}{$14.2 \mathrm{~B}$} \\
\hline & Amoxicillin & 10 & 16.5 & 12 & 15 & - & - & \\
\hline & $\begin{array}{l}\text { Without antibiotic } \\
\text { (nothing) }\end{array}$ & 11 & 16 & 13 & 14 & - & - & \\
\hline & Antibiotic alone & - & - & - & - & 18 & 9 & \\
\hline \multirow{4}{*}{ Mean } & Oxytetracycline & $18^{* *}$ & $23^{* *}$ & $20.5^{* *}$ & $21.5^{* *}$ & - & - & \multirow{4}{*}{18.1} \\
\hline & Amoxicillin & 13 & $22.8^{* *}$ & 15.8 & $20^{* *}$ & - & - & \\
\hline & $\begin{array}{l}\text { Without antibiotic } \\
\text { (nothing) }\end{array}$ & $14.5^{*}$ & $22^{*}$ & $17^{*}$ & $18.5^{*}$ & - & - & \\
\hline & Antibiotic alone & - & - & - & - & $18.5^{*}$ & $9^{*}$ & \\
\hline
\end{tabular}

$\left({ }^{*}\right)$ : presence of a synergistic interaction; $\left({ }^{* *}\right)$ : presence of a good synergistic interaction; $(-)$ : no test.

and Wang et al. identified, respectively, 38 and 27 components in C. cassia essential oil and found that cinnamaldehyde (30.67-90.74\%), copaene (27.71\%), and a-hexahydro-4 and 7-dimethyl-1-(1-methylethyl)-(1S-cis)naphthalene $(13.55 \%)$ were the main components of this essential oil $[36,37]$.

The results of the antibiogram in our study showed a resistance of $41.28 \%$ of the strains of Salmonella towards oxytetracycline, which is high when compared to the percentage found by Kassimi et al. (28.58\%) and that obtained by Ziyate et al. which was 25\% [38-40].

With regard to amoxicillin, 35\% of the strains were resistant, which is a high result when compared to the percentage found by Ziyate et al. [38] which was $21 \%$.

Almost $23 \%$ of the strains are resistant to enrofloxacin which is lower than the percentage found by Antunes et al. who reported that $75 \%$ of the strains isolated in Porto (Portugal) are resistant to one antibiotic or more and in particular to enrofloxacin [41].

Approximately, $13 \%$ of strains were resistant to trimethoprim-sulfamethoxazole, a result which remains low when compared to the rates reported by Gad and Hafez which is $59 \%$ in Germany [42]. For thiamphenicol, $9 \%$ of the strains are resistant which is due to the fact that it is no longer allowed in poultry.

A resistance of $5 \%$ to colistin $(25$ and $50 \mu \mathrm{g}$ ) was found. According to Humbert and Salvat, colistin remains among the sufficient number of antibiotics active on Salmonella [43]. And, a 5\% resistance to florfenicol could be explained by the fact that this molecule is not commonly used in poultry.

The aromatogram study showed that the essential oils and active products tested have antibacterial activity against the reference strain and the bacterial strains studied. C. cassia's products have been shown as the most active.

This study revealed that $S$. gallinarum is more sensitive to the essential oil of C. cassia $(27.65 \mathrm{~mm})$ than the strain of $S$. enteritidis $(16.25 \mathrm{~mm})$. However, carvacrol seems to be more active $(21.4 \mathrm{~mm})$ than the essential oil of $O$. compactum (17.7 mm).

The majority compounds are most often responsible for the antibacterial activity observed [44, 45]. Nevertheless, other studies show that in addition to major compounds, minority compounds play an important role in the antibacterial activity of the essential oil [46]. On the contrary, the sensitivity of a bacterium to essential oils depends on the properties of the microorganism itself $[44,47]$. 
The results of the minimum inhibitory concentration showed that the MIC values vary depending on the strain and on the natural product used, and the MIC of cinnamaldehyde was the lowest when compared to the strains tested (0.04 and $0.05 \%)$. These results are in agreement with those obtained in a previous work on Gram bacteria [48]. Nevertheless, the MIC values found remain higher than those obtained in our study, reflecting a better antibacterial activity of the essential oil of C. cassia $[49,50]$.

The results of the interaction of essential oils and antibiotics also demonstrated the potentiating effect of essential oils and their majority compounds on the activity of the tested antibiotics. The best synergistic activity with antibiotics was obtained with the essential oil of C. cassia (23 and $22.75 \mathrm{~mm}$ ) and its active product cinnamaldehyde (21.5 and $20 \mathrm{~mm}$ ). Our results are, on the whole, comparable to those reported for $O$. compactum, C. cassia, and their active principles [51].

The association of essential oils with antibiotics can be used to increase the antimicrobial spectrum and reduce and minimize the side effects of the antibiotic [52].

\section{Conclusions}

The essential oil of oregano and its majority component, carvacrol, and, above all, the essential oil of cinnamon and its majority component, cinnamaldehyde, are active in vitro against the reference strain (Salmonella CTP 8059) and the strains of Salmonella enteritidis and Salmonella gallinarum.

The lowest minimum inhibitory concentration (MIC) was obtained with cinnamaldehyde $(0.05 \%(\mathrm{v} / \mathrm{v}))$ against Salmonella enteritidis and $(0.04 \%(\mathrm{v} / \mathrm{v}))$ against Salmonella gallinarum compared with that of carvacrol $(0.014 \%$ and $0.01 \%(v)$ ) respectively, for the two bacterial strains.

The minimum bactericidal concentrations (MBCs) of the four products were very close to their respective MICs, indicating that the products studied are rather bactericidal.

The association of essential oils with antibiotics used in avian medicine indicates synergies, with the exception of the essential oil of O. compactum and carvacrol, which lend themselves much less to such interaction with amoxicillin. It should be noted that the resistance profile of strains isolated from poultry varies according to the antibiotic family and is comparable to the rates reported in other countries.

\section{Data Availability}

All the data generated or analyzed during this study are included within the article.

\section{Conflicts of Interest}

The authors declare that there are no conflicts of interest regarding the publication of this article.

\section{Acknowledgments}

The authors sincerely thank the Avian Pathology Unit at the Hassan II Agronomic and Veterinary Institute in Rabat and the Regional Center for Agronomic Research in Rabat for providing the equipment necessary for the accomplishment of this work.

\section{References}

[1] A. Fàbrega and J. Vila, "Salmonella enterica serovar typhimurium skills to succeed in the host: virulence and regulation," Clinical Microbiology Reviews, vol. 26, no. 2, pp. 308-341, 2013.

[2] N. F. C. Cianflone, "Salmonellosis and the GI tract: more than just peanut butter," Current Gastroenterology Reports, vol. 10, no. 4, pp. 424-431, 2008.

[3] S. J. McSorley, "Immunity to intestinal pathogens: lessons learned from Salmonella," Immunological Reviews, vol. 260, no. 1, pp. 168-182, 2014.

[4] M. I. George and M. M. Paul, "Salmonella serotyping using whole genome sequencing," Frontiers in Microbiology, vol. 9, p. 2993, 2018.

[5] S. Le Hello, "Salmonella: une bactérie multi-résistante aux antibiotiques dans nos assiettes," Journal des Anti-Infectieux, vol. 16, no. 4, pp. 192-198, 2014.

[6] J. K. Varma, K. D. Greene, J. Ovitt, T. J. Barrett, F. Medalla, and F. J. Angulo, "Hospitalization and antimicrobial resistance in salmonella outbreaks, 19842002," Emerging Infectious Diseases, vol. 11, no. 6, p. 943, 2005.

[7] Y. Hu, X. Yang, J. Li et al., "The bacterial mobile resistome transfer network connecting the animal and human microbiomes," Applied and Environmental Microbiology, vol. 82, no. 22, pp. 6672-6681, 2016.

[8] EFSA, Rapport de l'EFSA et de l'ECDC, EFSA, Parma, Italy, 2014, https://www.efsa.europa.eu/fr/press/news/140325.

[9] EFSA/ECDC, Rapport sur la résistance aux antimicrobiens dans les bactéries zoonotiques, EFSA/ECDC, Solna, Sweden, 2016, https://securite-alimentaire.public.lu/fr/point_focal/ Publications-EFSA/publications/2016/02/Publication-EFSA. html.

[10] EFSA, La Résistance Aux Antimicrobiens, EFSA, Parma, Italy, 2019, https://www.efsa.europa.eu/fr/press/news/190226.

[11] N. Amajoud, N. Skalli senhaji, I. Bouchrif, B. Karraouan, M. El maadoudi, and J. Abrini, "La résistance des souches de salmonella isolées à partir des denrées alimentaires dans la ville de Tétouan. Société Marocaine de Microbiologie Médicale-SMAMM-2015. La 6ème édition de ses Journées Scientifiques, sous le thème "Les Bactéries Multirésistantes», le 3 et 4 avril," 2015, http://smamm.ma/6emes-journeesscientifiques-2015/.

[12] O. Elared, A. Amara, M. Faid, M. A. Alaoui, and E. H. Tahri, "Antibiorésistance des souches de Salmonella enteritidis isolées dans la zone de Rabat-Casablanca à partir de l'œuf de consommation, de l'aliment et des fientes de poules pondeuses," Actes de l'Institut Agronomique et Vétérinaire Hassan II, vol. 21, no. 3, pp. 147-150, 2001.

[13] T. Berradi, B. Karraouan, O. Charafeddine, B. Bouchrif, and N. Abouchoaib, "Résistance aux fluoroquinolones des Salmonella Kentucky isolées de produits alimentaires d'origine animale (Casablanca, Maroc)," Médecine et Maladies Infectieuses, vol. 48, no. 7, pp. 488-489, 2018.

[14] A. Remmal, "Activités antimicrobiennes et antivirales des huiles essentielles d'origan, de girofle et de thym," Faculty of Sciences Dhar El Mehraz, Sidi Mohamed Ben Abdellah University, Fez, Morocco, Thèse Doctorale, 1994.

[15] M. Lahlou, "Methods to study the phytochemistry and bioactivity of essential oils," Phytotherapy Research, vol. 18, no. 6, pp. 435-448, 2004. 
[16] A. Chafai Elalaoui, A. Boukil, M. Bachar, D. Lkhoumsi, and A. Guermal Abdenasse, Manuel des bonnes pratiques de collecte de l'origan "Origanum Compactum ", Projet PAM, Naples, Italy, 2014, https://www.fellah-trade.com/ressources/ pdf/MBPC_Origan_Francais.pdf.

[17] P. N. Ravindran, K. Nirmal Babu, and M. Shylaja, Cinnamon and Cassia, the Genus Cinnamomum, CRC Press, Boca Raton, FL, USA, 2004.

[18] S. Nassik, N. El-aamili, M. Benjelloun et al., "Detection and identification of salmonella serovars from laying hen farms in Morocco by bacteriology and rapid tests," International Journal of Agriculture, Environment and Bioresearch, vol. 4, no. 2, pp. 139-142, 2019.

[19] Council of Europe, European Pharmacopeia, vol. 1, Europeann Council, European Directorate for the Quality of the Medicines (EDQM), Strasbourg, France, 5th edition, 2005.

[20] J. B. Patel, F. R. Cockerill, J. Alder et al., Performance Standards for Antimicrobial Susceptibility Testing; Twenty-Fourth Informational Supplement (M100-S24), Clinical and Laboratory Standards Institute, Wayne, PA, USA, 2014.

[21] I. Wiegand, K. Hilpert, and R. E. W. Hancock, "Agar and broth dilution methods to determine the minimal inhibitory concentration (MIC) of antimicrobial substances," Nature Protocols, vol. 3, no. 2, pp. 163-175, 2008.

[22] C. M. Mann and J. L. Markham, "A new method for determining the minimum inhibitory concentration of essential oils," Journal of Applied Microbiology, vol. 84, no. 4, pp. 538-544, 1998.

[23] E. Halawani, "Antibacterial activity of thymoquinone and thymohydroquinone of Nigella sativa L. And their interaction with some antibiotics," Advances in Biological Research, vol. 3, pp. 148-152, 2009.

[24] S. Toroglu, "In-vitro antimicrobial activity and synergistic/ antagonistic effect of interactions between antibiotics and some spice essential oils," Journal of Environmental Biology, vol. 32, no. 1, pp. 23-29, 2011

[25] D. F. Huang, J.-G. Xu, J.-X. Liu, H. Zhang, and Q. P. Hu, "Chemical constituents, antibacterial activity and mechanism of action of the essential oil from cinnamomum cassia bark against four food-related bacteria," Microbiology, vol. 83, no. 4, pp. 357-365, 2014.

[26] S. Schwartz, A. Cloeckaert, and M. C. Roberts, "Mechanisms and spread of bacterial resistance to antimicrobial agents," in Antimicrobial Resistance in Bacteria of Animal Origin, F. M. Aarestrup, Ed., pp. 73-98, ASM Press, Washington, DC, USA, 2006.

[27] M. R. Meena and V. Sethi, "Antimicrobial activity of the essential oils from spices," Journal of Food Science \&Technology, vol. 31, pp. 68-70, 1994.

[28] A. Ela, N. S. el-Shaer, and N. B. Ghanem, "Antimicrobial evaluation and chromatographic analysis of some essential and fixed oils," Die Pharmazie, vol. 51, no. 12, pp. 993-995, 1996.

[29] R. J. W. Lambert, P. N. Skandamis, P. J. Coote, and G.-J. E. Nychas, "A study of the minimum inhibitory concentration and mode of action of oregano essential oil, thymol and carvacrol," Journal of Applied Microbiology, vol. 91, no. 3, pp. 453-462, 2001.

[30] P. Rui-song, Z. Feng, J. Bao-ping, and X. Jing, "Evaluation of combined antibacterial effects of eugenol, cinnamaldehyde, thymol, and carvacrol against $E$. coli with an improved method," Journal of Food Science, vol. 74, no. 7, pp. 379-383, 2009.
[31] F. Ben-Hammou, S. N. Skali, M. Idaomar, and J. Abrini, "The antimicrobial effect of Origanum compactum essential oil nisin and their combination against Escherichia coli in tryptic soy broth (TSB) and in sheep natural sausage casings during storage at 25 and $7^{\circ} \mathrm{C}$," African Journal of Biotechnology, vol. 10, no. 71, pp. 15998-16005, 2011.

[32] C. O. Van Den Broucke and J. A. Lemli, "Chemical investigation of the essential oil of Origanum compactum," Planta Medica, vol. 38, no. 3, pp. 264-266, 1980.

[33] Y. Laghmouchi, O. Belmehdi, N. S. Senhaji, and J. Abrini, "Chemical composition and antibacterial activity of Origanum compactum benth. Essential oils from different areas at northern Morocco," South African Journal of Botany, vol. 115, pp. 120-125, 2018.

[34] J. Choi, K.-T. Lee, H. Ka, W.-T. Jung, H.-J. Jung, and H.-J. Park, "Constituents of the essential oil of the Cinnamomum cassia stem bark and the biological properties," Archives of Pharmacal Research, vol. 24, no. 5, pp. 418-423, 2001.

[35] S. Geng, Z. Cui, X. Huang, Y. Chen, D. Xu, and P. Xiong, "Variations in essential oil yield and composition during Cinnamomum cassia bark growth," Industrial Crops and Products, vol. 33, no. 1, pp. 248-252, 2011.

[36] L. Tao, J. Huang, and H. Mai, "A comparison of the constituents of essential oils from Cinnamomum cassia extracted by supercritical fluid extraction and steam distillation," The Journal of Analysis, vol. 23, pp. 65-67, 2004.

[37] L. Wang, Z. Wang, T. Li, X. Zhou, L. Ding, and H. Zhang, "Rapid extraction and analysis of essential oil from cinnamomum cassia presl," Chemical Research in Chinese Universities, vol. 24, no. 3, pp. 275-280, 2008.

[38] N. Ziyate, B. Karraouan, A. Kadiri, S. Darkaoui, A. Soulaymani, and B. Bouchrif, "Prevalence and antimicrobial resistance of Salmonella isolates in Moroccan laying hens farms," Journal of Applied Poultry Research, vol. 25, no. 4, pp. 539-546, 2016.

[39] R. Helmuth, "Antibiotic resistance in Salmonella," in Salmonella in Domestic Animals, C. Wray and A. Wray, Eds., pp. 89-106, CABI Publishing, Oxfordshire, UK, 2000.

[40] F. R. Ungemach, D. Müller-Bahrdt, and G. Abraham, "Guidelines for prudent use of antimicrobials and their implications on antibiotic usage in veterinary medicine," International Journal of Medical Microbiology, vol. 296, pp. 33-38, 2006.

[41] P. Antunes, C. Réu, J. C. Sousa, L. Peixe, and N. Pestana, "Incidence of Salmonella from poultry products and their susceptibility to antimicrobial agents," International Journal of Food Microbiology, vol. 82, no. 2, pp. 97-103, 2003.

[42] A. Rajaonarivelo, "Etude de portage de salmonelle spp chez la poule pondeuse à l'âge de reforme au maroc," Thèse de Doctorat Vétérinaire, 2016.

[43] F. Humbert and G. Salvat, "Risques de transmission des salmonelles en aviculture: détection et prévention en Europe," Revue Scientifique et Technique de l'OIE, vol. 16, no. 1, pp. 83-90, 1997.

[44] H. J. D. Dorman and S. G. Deans, "Antimicrobial agents from plants: antibacterial activity of plant volatile oils," Journal of Applied Microbiology, vol. 88, no. 2, pp. 308-316, 2000.

[45] D. Kalemba and A. Kunicka, "Antibacterial and antifungal properties of essential oils," Current Medicinal Chemistry, vol. 10, no. 10, pp. 813-829, 2003.

[46] M. C. Rota, A. Herrera, R. M. Martínez, J. A. Sotomayor, and M. J. Jordán, "Antimicrobial activity and chemical 
composition of Thymus vulgaris, Thymus zygis and Thymus hyemalis essential oils," Food Control, vol. 19, no. 7, pp. 681-687, 2008.

[47] H. Nikaido, "Molecular basis of bacterial outer membrane permeability revisited," Microbiology and Molecular Biology Reviews, vol. 67, no. 4, pp. 593-656, 2003.

[48] S.-T. Chang, P.-F. Chen, S.-Y. Wang, and H.-H. Wu, "Antimite activity of essential oils and their constituents from Taiwania cryptomerioides," Journal of Medical Entomology, vol. 38, no. 3, pp. 455-457, 2001.

[49] A. O. Gill and R. A. Holley, "Mechanisms of bactericidal action of cinnamaldehyde against Listeria monocytogenes and of eugenol against L. monocytogenes and Lactobacillus sakei," Applied and Environmental Microbiology, vol. 70, no. 10, pp. 5750-5755, 2004.

[50] R. Di Pasqua, G. Betts, N. Hoskins, M. Edwards, D. Ercolini, and G. Mauriello, "Membrane toxicity of antimicrobial compounds from essential oils," Journal of Agricultural and Food Chemistry, vol. 55, no. 12, pp. 4863-4870, 2007.

[51] W. T. Langeveld, E. J. A. Veldhuizen, and S. A. Burt, "Synergy between essential oil components and antibiotics: a review," Critical Reviews in Microbiology, vol. 40, no. 1, pp. 76-94, 2013.

[52] O. A. Aiyegoro and A. I. Okoh, "Use of bioactive plant products in combination with standard antibiotics: implications in antimicrobial chemotherapy," Journal of Medicinal Plant Research, vol. 3, no. 13, pp. 1147-1152, 2009. 